\title{
Evaluation of Disaster Emergency Handling Policy in Bangkalan District, East Java Province
}

\author{
Wahid Hidayat \\ Student of Doctor Study Program of Administration Science- FISIP. University 17 Agustus 1945 Surabaya, \\ Semolowaru Street No 45 Surabaya city - Indonesia
}

Arif Darmawan

Rachmawati Novaria

\begin{abstract}
This research is an evaluation of disaster emergency management policies in Bangkalan Regency, East Java Province.Using a qualitative research approach. The results showed that the flood disaster management by Bangkalan BPBD had not run optimally, there were still problems and obstacles faced in the implementation. This is marked by Disaster Prevention (floods, earthquakes, etc.) Disaster emergency management, disaster rehabilitation and reconstruction, many problems are still found.The conclusion is that the Disaster Emergency Management Policy in Bangkalan Regency, East Java Province, is already good, only at the time of implementation it still needs to be reevaluated, because the community still complains, the apparatus handling it has not performed their duties optimally (less professional).Researcher's suggestion: to optimize the prevention of natural disasters, prevention needs to be done as best as possible by implementing prone maps, maximum socialization; There must be personnel who support the implementation of tasks and adequate equipment so that they can carry out their duties as best they can; The need for facilities and infrastructure in order to provide good treatment for disaster victims; There must be coordination between the government and the community in accompanying disaster management; The need for equity in the implementation of disaster management both in terms of prevention, emergency or rehabilitation and reconstruction.
\end{abstract}

Keywords: evaluation, policy, disaster emergency

DOI: $10.7176 / \mathrm{PPAR} / 10-1-02$

Publication date: January $31^{\text {st }} 2020$

\section{I.Introduction}

According to the hazard assessment matrix generated by threats and natural disasters in Bangkalan Regency, the flood disaster occupies the highest position both on a probability scale or how likely it is that the disaster will occur and the scale of the impact that will be caused by the flood disaster. Furthermore, from a disaster perspective, that in every disaster event, whatever its form, including flood and or potential disasters in Bangkalan District, the poor and rich groups will get the same risk, even the poor and vulnerable, often being the group most affected by the disaster. However, it is not uncommon, that rich people who are affected by disasters at that time can also become poor. The impact of the series of disasters that occurred in Bangkalan District shows that there is still a lot of work to be done by various parties, governments, communities and the business community as well as local communities, in an effort to reduce the risks and impacts of disasters.

One of the strategic efforts that must be continually pursued is to encourage a culture of community awareness to be responsive, and resilient in the face of disasters. Responsive, means sensitive or at least recognize the symptoms and potential disasters that occur in the region. The tradition of the community around disaster-prone areas that have local wisdom recognizes the symptoms and potential disasters, becoming one part of the community's own responsiveness. Tangguh means having resilience in the effort to deal with threats or catastrophic events, and independently anticipate and prepare optimally when a disaster occurs. In essence, society naturally transforms in accordance with the dynamics (experience, threats, value shifts, the influence of interactions, technological changes and also the change of generations) they experience. The attitude towards anything that befalls a community group is a stimulus that breeds resilience and resilience, which results in internal resilience. External assistance does not constitute the majority of community resilience energy.

Nationally, there are 2 (two) main issues regarding disaster management, namely: (i) the inadequate performance of disaster management, this is related to capacity constraints in the implementation of emergency response and efforts to rehabilitate and reconstruct post-disaster areas, and (ii) still low awareness of disaster risk and the low understanding of disaster preparedness, including low awareness of disaster risk reduction efforts and preparedness in dealing with disasters. On the other hand, the integration of Disaster Risk Reduction (DRR) in Development Planning is still constrained by a number of things, including gaps in community perceptions, as well as government officials about risk reduction, which so far has been limited to understanding the emergency response, lack of socialization of disaster risk reduction to stakeholders, and limited institutional, human 
resource and funding capacity for disaster risk reduction. In an effort to reduce a number of disaster risk reduction problems, the 2015-2019 RPJMN document states that the target achieved in disaster management is to decrease the disaster risk index in high-risk growth centers, while the policy direction is to reduce disaster risk and increase capacity government, regional governments and the community in dealing with disasters.

Related to the policy on emergency handling and or disaster preparedness, in the 2015-2019 National Disaster Management Plan (Renas PB) it is stated that there are still a number of camps in efforts to increase preparedness and emergency response to deal with disasters independently and proactively. This problem occurs because it is related to: (i) limited institutional capacity, disaster evacuation infrastructure in national priority areas, (ii) system and implementation of guidelines and standard mechanisms for improving community preparedness in the face of disaster, (iii) not yet holding preparedness training exercises national level in stages, gradually and continuously in accordance with Indonesian National Standards (SNI), (iv) the not yet developed Disaster Preparedness Culture which guarantees the independence of community resource mobilization for disaster preparedness, (v) the system and mechanism of resource mobilization during emergency response is not yet established national level disasters, (vi) system and mechanism as well as supporting infrastructure and logistics have not yet been prepared in the handling of disaster emergency, (vii) human resources are still weak in the use of guidelines for the implementation of rapid studies and determination of disaster emergency status, (viii) not yet optimal socialization of settlement mechanisms and the status of disaster emergency, especially in the chain of command control, (ix) the implementation of periodic training and certification of Indonesian Disaster Management Rapid Response Units (SRC PB) has not yet been carried out, (x) efforts have not been made to strengthen the Emergency Response Command System based on the National Framework for Disaster Emergency Response .

Based on the description above, the problems of this study can be formulated as follows: 1). What factors influence disaster management in Bangkalan Regency? 2). How to evaluate disaster management policies in Bangkalan Regency? 3). Disaster emergency management model that is suitable with Bangkalan District?

\section{Literature Review}

\subsection{Public Policy Evaluation}

Evaluations are usually intended to assess the effectiveness of public policies to be accountable to their constituents. The extent to which objectives are achieved and to see the extent of the gap between expectations and reality. According to Wayne (1997); Anderson (1978); Winarno (2008), in general, policy evaluation can be said as an activity that involves the estimation or assessment of policies that include the substance, implementation and impact of the implementation of the policy. According to Lester and Stewart (2000); Winarno (2008) policy evaluation can be divided into two different tasks, the first task is to determine the consequences of a policy by describing its impact. While the second task is to assess the success or failure of a policy based on predetermined standards or criteria. Policy evaluation is a matter of fact in the form of measurement and evaluation of the stages of the implementation of the policy as well as the outcome (outcome) or impact (impact) of the operation of a particular policy or program, so determining the steps that can be taken in the future.

Furthermore, James Anderson in Winarno (2008) divides policy evaluation into three types, each type of evaluation that is introduced is based on the evaluators' understanding of evaluations, as follows: First Type, policy evaluation is understood as a functional activity. If policy evaluation is understood as a functional activity, policy evaluation is seen as an activity that is as important as the policy itself. The Second Type, is the type of evaluation that focuses on the operation of certain policies or programs. This type of evaluation talks more about honesty or efficiency in implementing programs. Whereas the Third Type, the type of systematic policy evaluation, this type of policy looks objectively at the policy programs implemented to measure their impact on the community and see the extent to which the stated objectives have been achieved.

The impact of policies has several dimensions and all of them must be considered in discussing evaluation. According to Winarno (2008) there are at least five dimensions that must be discussed in calculating the impact of a policy. These dimensions include: (a) the impact of the policy on public matters and the impact of the policy on the people involved; (b) the policy may have an impact on circumstances or groups outside the policy goals or objectives; (c) the policy might have an impact on current and future conditions; (d) evaluation also involves another element, namely direct costs incurred to finance public policy programs; and (e) indirect costs incurred by the community due to public policies.

Evaluating policy as a functional activity is as old as the policy itself. Basically when someone wants to evaluate the impact of the policy, there are three things that need to be considered, namely: (i) evaluating the policy trying to provide valid information about the performance of the policy. Evaluation in this case serves to assess aspects of the instrument (how to implement) policy and assess the results of the use of the instrument; (ii) policy evaluation seeks to assess the certainty of goals or targets with the problem encountered. In this function, policy evaluation focuses on the substance of existing public policies. The basic assumption used is that public 
policies are made to resolve existing problems. What often happens is that the goal is reached but the problem is not solved; and (iii) policy evaluation seeks to contribute to the evaluation of other policies especially in terms of methodology. That is, an evaluation of the policy strived to produce recommendations from assessments made on the policy being evaluated.

Simple policy evaluation according to William (2003); Agustino (2008), regarding the production of information about the values or benefits of the policy. When it is of value in evaluating problem solving, the results contribute to the goals and objectives of the evaluator, specifically, and other users in general. This is said to be beneficial if the policy evaluation function is well fulfilled. One function of policy evaluation is that it must provide valid and reliable information about policy performance. Furthermore, according to Samudra in Nugroho (2003), evaluation of public policy has four functions, namely: (i) explanation, through evaluation the reality of program implementation can be portrayed and a generalization can be made of the patterns of relationships between the various dimensions of reality that are observed. From this evaluation the evaluator can identify problems, conditions, and actors that support the success or failure of the program; (ii) compliance, through evaluation it can be seen whether the actions taken by the actors, both the bureaucracy and other actors are in accordance with the standards and procedures set by the policy; (iii) auditing, through evaluation can be known, whether the output actually reaches the target group of the policy, or there is actually a leak or deviation; and (iv) accounting, by evaluating the socio-economic consequences of the policy.

\subsection{Policy Evaluation Indicator}

Budi Winarno (2008), quoting Edward A. Sucman's statement that policy evaluation on the other hand is more on the practical level by proposing six steps in policy evaluation, namely: (i) identifying the program objectives to be evaluated; (ii) analysis of the problem; (iii) description and standardization of activities; (iv) measurement of the level of change that occurs; (v) determine whether the observed change is a result of the activity or due to other causes; and (vi) several indicators to determine the existence of an impact. The results of the evaluation will be analyzed as a consideration for policy makers to make adjustments or changes in order to improve the policy. This shows that a public policy is not permanent but requires adjustment, because the policy is strongly influenced by political, social, economic, cultural, technological and information factors that are always dynamic. In carrying out policy evaluations, general criteria are used to provide direction for evaluators . The criteria formulated will be used as a benchmark in determining whether a policy is successful or failed. Dunn (2000) describes the criteria for policy evaluation which includes 6 (six) types as follows: (1) Effectiveness, with regard to whether an alternative achieved the expected results or achieved the objectives of the action. Effectiveness that is closely related to technical rationality, is always measured by the product or service unit or its monetary value. (2) Efficiency, with regard to the amount of effort required to increase a certain level of effectiveness. Efficiency, which is synonymous with economic rationality, is the relationship between effectiveness and effort, which is generally measured by monetary costs. (3) Adequacy, with regard to how far the level of effectiveness satisfies the needs, values or opportunities that create problems. Adequacy criteria emphasize the strong relationship between policy alternatives and expected outcomes. (4) Equity, this Indicator is closely related to legal and social rationality and points to the distribution of effects and effort between different groups in society. Smoothing-oriented policies are policies that are consequently (for example, service units or monetary benefits) or business (eg monetary costs) fairly distributed. Policies designed to distribute income, educational opportunities or public services are sometimes recommended on the basis of similarity criteria. The criterion of equality is closely related to competing conceptions, namely justice or fairness and to ethical conflicts around an adequate basis for distributing risks in society. (5) Responsiveness, With regard to how far a policy can satisfy the needs, preferences, or values of certain groups of society. Responsiveness criteria are important because analyzes that can satisfy all other criteria - effectiveness, efficiency, adequacy, equality - still fail if they have not responded to the actual needs of the group that should have benefited from a policy. (6) Appropriateness. closely related to substantive rationality, because the question of the appropriateness of policies does not concern individual units of criteria but two or more criteria together. Accuracy refers to the value or price of program objectives and to the strength of the assumptions underlying these goals.

While Abdul Wahab (1997); Marsh, and Buckle (2001), argued that in principle that the substance of the evaluation of policy evaluation or evaluation content, consists of 3 (three) aspects, namely: (i) Efficiency, which describes the suitability of the proportion of resource use in implementing policies / the program with the results of the implementation of the policy / program that has been achieved, as well as the factors that influence the efficiency of the implementation of the said policy / program; (ii) Effectiveness, which explains the accuracy of the results achieved by implementing the policy / program with the plans and or objectives set, and the factors that influence the effectiveness of the implementation of the policy / program; and (iii) Effect, which is the impact of implementing policies / programs, both positive and negative, especially for benefeceries (benefit pickers) and / or target groups, and the realization of program implementation (in the field) able to make a real contribution to the stated policy / program goals ( Enders J 2001; Buckle, 1999). 


\section{Research MethodesAndData Analysis 3.1 Research Approach}

This study uses an approach based on qualitative research. With a qualitative approach it is expected to be able to produce an in-depth description of speech, writing and / or behavior that can be observed from an individual, group, society, an organization / community in a particular context which is studied from a holistic, comprehensive and holistic perspective. As stated by Lincoln \& Guba (1989) that qualitative research is indeed most appropriate for carrying out research activities that are exploratory in nature, because the type and design of research on naturalistic approaches are generally relatively more flexible in capturing and establishing research variables.

\subsection{Data Sources and Analysis}

Typically in qualitative research, known as a purposive sample focusing on selected informants who are rich in cases for in-depth studies. Qualitative research requires the selection of "samples" purposively (purposeful sampling). The main purpose of qualitative research is to describe reality as it is, gain an understanding of the meaning of that reality, and develop a theoretical explanation about it. Therefore, in the selection of "samples", researchers do not prioritize the benchmark population representation, but the depth and completeness of understanding of the research problem. As the implication, the "sample" must be chosen deliberately and usually in small quantities. A person is chosen as a "sample" only if he contributes an understanding of the aspect of the problem under investigation. This is the opposite of quantitative research. This type of research aims to show the relationship between variables for the purposes of verifying a generalization or predictive theory. Therefore the quantitative research sample must represent the population. This is sought by selecting a random sample of large numbers (random probability sampling). As for the purpose of being used as informants and key informants in this activity are: (i) Regional Secretary as Head of BPBD (ii) Incindent Commander (IC) (iii) ) Kalaksa BPBD Kab. Bangkalan (iv) Coordinator of Emergency Response Post; (iii) Emergency Affairs \& Logistics BPBD Kab. Bangkalan; (iv) Customary figures / community flood affected locations in Kab. Bangkalan; (v) Local / NonLocal NGOs involved in disaster emergency management in the district. Bangkala; (vi) government and private agencies / agencies involved in disaster emergency management in Bangkalan Regency.

\section{Results, Discussion, Implication And Research Proposition}

\subsection{Discussion}

Regional Disaster Management Agency is one of the agencies that carry out disaster management in Bangkalan Regency including flood, earthquake and other disasters. In this case, the disaster management carried out by the government agency is to carry out prevention, emergency response, rehabilitation and reconstruction, in accordance with the Disaster Emergency Management Policy in Bangkalan Regency. Disaster management is intended to be able to minimize damage and provide comfort to residents in their residence. With the importance of such mitigation, the Evaluation of Disaster Management Policy in Bangkalan Regency, East Java Province, needs to be analyzed. To analyze this, researchers used four aspects, namely Disaster Prevention, Disaster Emergency Management, Disaster Rehabilitation, Disaster Impact Reconstruction.

From the results of research on disaster prevention carried out by the Bangkalan BPBD agency, found various obstacles in the implementation of disaster prevention. As for the routine monitoring carried out by the $\mathrm{BPBD}$, it has not been optimal, it is seen that there are no monitoring reports in terms of administration, nor is there a guard post and monitoring reports from the task force guarding the natural disaster area. Guard posts should be built in each district, in order to carry out routine monitoring of areas that are frequently affected by disasters. Other indicators such as the implementation of disaster-prone mapping, especially floods, earthquakes, etc., do not yet exist because they are still in the assessment stage, so that BPBD agencies have not been able to convey disaster-prone information in Bangkalan Regency, and also the implementation of preparedness training in prevention and disaster management, has not been felt fully by the community, proven by the training that is not sustainable and the training has not been evenly obtained or felt by all people in the disaster area in particular, so that in this case it can be said that the implementation of prevention carried out by Bangkalan $\mathrm{BPBD}$, not working properly. In addition it is necessary to hold socialization with different methods, so that it can be understood and applied by the community in Bangkalan Regency.

From the disaster emergency management it can be concluded, that the implementation of disaster emergency management has been running but has not been carried out as expected by the community in Bangkalan Regency. Problems that often occur such as personnel who have not been seen helping the community when a disaster occurs, this results in delays in reducing the risk of disasters, such as floods. BPBD agencies should need to add the number of personnel or task forces, and conduct training in improving the capacity and quality of personnel. Apart from that, inadequate equipment, facilities and infrastructure at the time 
of the disaster did not yet fully exist such as tents that were still lacking, many rubber boats were damaged and other equipment that did not yet exist, thus hampering the course of disaster management in Bangkalan Regency.

From the results of research on the evaluation of disaster management through rehabilitation and reconstruction carried out by the Bangkalan BPBD agency, various obstacles were found in implementing disaster prevention. Problems that often occur, such as the coordination carried out between the government and the community have not been going well and optimally, in order to determine the disaster-prone points so that it is still difficult to carry out post-disaster recovery. There are still many buildings that have not been rehabilitated for a long time, such as dykes and culverts that cause the dam to burst. Reconstruction and rehabilitation has not been evenly distributed, and there are still a number of points that have not been rehabilitated or reconstructed.

\subsection{Research Implications}

Based on the research findings previously presented, the results of this study provide theoretical implementations and important contributions in enriching public policy theory especially Fredrick's (1982) concept; Anderson (1975); Easton (1965) in public policy which states that policy as a guideline for carrying out activities chosen by a person or group of people and can be implemented as well as influencing a large number of people in order to achieve a certain goal. Parker (1975), states that public policy is a particular area or field and the actions of the government as a subject of comparative study and critical study, which include, among other things, different actions and principles and carefully analyze the possibility of a cause and effect relationship in the context of a particular discipline of thinking such as economics, science or politics

Enrichment of policy evaluation theory, especially the concept of James Anderson in Winarno (2008), which states that policy evaluation is a matter of fact in the form of measurement and evaluation of the stage of policy implementation as well as the outcome or impact of the operation of a policy or program certain, so determining the steps that can be taken in the future.

Research is able to show the contribution to disaster management theory, such as the concept put forward by Nurjanah (2012), that disaster management is knowledge that studies disasters and all aspects related to disasters, especially disaster risk and how to avoid disaster risk, disaster management is a dynamic process of working management functions that we know so far such as planning, organizing, actuating and controlling. The theory contained in Wikipedia, Emergency Management (2007), that disaster management is a continuous process where every individual, group and community try to manage risks to avoid or improve the impact of a disaster resulting from a disaster. This research is able to show empirically that the flood disaster management by Bangkalan BPBD has not run optimally, there are still problems and obstacles encountered in the implementation. Therefore, the Bangkalan BPBD is expected to be able to coordinate comprehensively about the handling of disaster prevention (floods, landslides, earthquakes and others), disaster emergency management, rehabilitation and reconstruction of disasters, so that the existence of Bangkalan BPBD can be clearly enjoyed by the community.

The results of this study provide practical implications to the Bangkalan BPBD that to optimize natural disaster relief, especially floods, landslides, earthquakes and others, the Bangkalan BPBD needs to do the best possible prevention by carrying out hazard map making, maximum socialization. It should also coordinate well between the government and the community in dealing with disaster management. The need for equity in the implementation of disaster management both in terms of prevention, emergency or rehabilitation and reconstruction.

The results of this study also found that in the evaluation of policies especially in the aspects of rehabilitation and reconstruction of disasters, it appeared that it had not been running optimally. Therefore Bangkalan BPBD needs to coordinate with the people affected by the disaster, through intense communication so that information about the impact of the disaster is obtained clearly, so that the BPBD can carry out rehabilitation and reconstruction of disasters in accordance with community needs.

\subsection{Critical Theory and Proposition}

Anderson (Winarno, 2008), states that policy evaluation is an activity that involves the estimation or evaluation of policies that include the substance, implementation and impact of the implementation of the policy. According to Lester and Stewart (Winarno, 2008), that policy evaluation can be divided into two different tasks, namely: first is to determine the consequences of a policy by describing its impact. While the second task is to assess the success or failure of a policy based on predetermined standards or criteria. Policy evaluation is a matter of fact in the form of measurement and evaluation of the stages of the implementation of the policy as well as the outcome (outcome) or impact (impact) of the operation of a particular policy or program, so determining the steps that can be taken in the future. From the research results of the policy evaluation on disaster management in Bangkalan Regency, East Java Province, the research proposition is as follows: (1) Evaluation of disaster management policies in Bangkalan Regency can find out the effectiveness of the implementation of disaster management policies in Bangkalan Regency. (2) Evaluation of disaster management policies in Bangkalan Regency can 
minimize the impact of disasters on the community. (3) Evaluation of disaster management policies in Bangkalan Regency can determine the policy steps taken in the future.

\section{Conclusions and Recommendations}

Based on the results of the discussion carried out in the previous chapter, it can be described several notes as follows: that the flood disaster management by Bangkalan BPBD has not been running optimally, there are still problems and obstacles encountered in the implementation. This is marked by Disaster Prevention (floods, earthquakes, etc.) Disaster emergency management, disaster rehabilitation and reconstruction, many problems are still found.

In the aspect of disaster prevention, problems are still encountered such as the implementation of making maps of disaster prone, especially floods, earthquakes and others that do not yet exist, the implementation of routine monitoring that has not been seen by the community and the preparedness training has not been felt by the community so that prevention and handling of disasters has not been felt completely by the community. The need for the application of more practical methods of socialization so that people more easily understand.

In the aspect of disaster emergency management, it seems that it has not been running optimally, the evidence is that personnel who have not come down too badly helped the community during a disaster, such as flooding, inadequate equipment such as tents that were still lacking, and many rubber boats that were damaged, facilities and infrastructure during the disaster. not yet fully there.

In the aspect of disaster rehabilitation and reconstruction, it seems that it has not been running optimally, as evidenced by the coordination between the government and the community that has not been going well and optimally to determine disaster prone points, there are still many buildings that have not been rehabilitated for a long time, such as embankments and culverts. , the implementation of reconstruction and rehabilitation has not been evenly distributed.

So, flood disaster management by Bangkalan BPBD is still not optimal, even almost not felt by the community at all. Therefore, we conclude that the Disaster Emergency Management Policy in Bangkalan Regency, East Java Province, is already good, it's just that at the time of implementation it still needed to be reevaluated, because the community still complained, the apparatus handling it had not performed its duties optimally (less professional).

Based on the analysis carried out in the previous chapters, the researcher provides the following recommendations: (1) To optimize the handling of natural disasters, especially floods, earthquakes and other disasters in Bangkalan Regency, it is necessary to do the best possible prevention by carrying out the making of hazard maps, maximum socialization. (2) There must be personnel who support the implementation of duties and adequate equipment so that they can carry out their duties as best they can. (3) The need for facilities and infrastructure to be able to provide good treatment for disaster victims. (4) There must be coordination between the government and the community in dealing with disaster management

The need for equity in the implementation of disaster management both in terms of prevention, emergency or rehabilitation and reconstruction.

\section{Refernces}

[1] Abdul Wahab, S., 1999, Analisis Kebijakan Publik : Teori dan Aplikasinya. PT Danar Wijaya. Malang.

[2] Anderson, James E. 1978. Public Policy Making. New York: Holt, Rinehart andWinston, 2nd ed.

[3] Buckle P 1998/9, 'Re-defining community and vulnerability in the context of emergency management'. Australian Journal of Emergency Management 13(4) 21-26.

[4] Dunn, William N. 2000. Analisis Kebijakan Publik. Yogyakarta : Gadjahmada University Press

[5] Enders J 2001, 'Measuring community awareness and preparedness for emergencies'. Australian Journal of Emergency Management 16 (3): 52-58.

[5] Lester, James P dan Steward, Josep Jr.2000. Public Policy:AnEvolutionari Approach. Belmont: Wadsworth

[6] Lincoln, Yvonna S \&Egon G. Guba.1989. Naturalistic Inquiry .California: Sage

[7] Marsh G, Buckle P 2001, 'Community: the concept of community in the risk and emergency management context'. Australian Journal of Emergency Management 16(1): 5-7.

[8] Nurjanah,dkk. 2012. ManajemenBencana. Bandung. ALFABETA.hlm 20-21.

[9] Wayne, Parsons, 1997. Public Policy :An introduction to the teory and practice of policy analysis, Cambridge: Edward Elgar Publising.

[10] William N., Dunn, 2003. AnalisisKebijakanPublik. Yogyakarta: GadjahMada University Press.

[11] Winarno, Budi, 2008. KebijakanPublik:Teoridan Proses, Jakarta: PT Buku Kita.

[12] Wikipedia, Emergency Management (2007) 